\title{
The effectiveness of a high-intensity games intervention on improving indices of health in young children
}

Article in Journal of Sports Sciences · May 2015

DOI: 10.1080/02640414.2015.1048521 · Source: PubMed

CITATIONS

3

5 authors, including:

\section{Danielle Lambrick}

University of Southampton

63 PUBLICATIONS 307 CITATIONS

SEE PROFILE

Lee Stoner

University of North Carolina at Chapel Hill 147 PUBLICATIONS 527 CITATIONS

SEE PROFILE

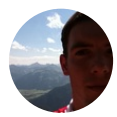

Sebastian Kaufmann

University of Wuerzburg

6 PUBLICATIONS 2 CITATIONS

SEE PROFILE

James Faulkner

The University of Winchester

80 PUBLICATIONS 760 CITATIONS

SEE PROFILE 
The effectiveness of a high intensity games intervention on improving indices of health in young

\section{children}

Lambrick $^{1}$, D., Westrupp ${ }^{2}$, N., Kaufmann ${ }^{3}$, S., Stoner ${ }^{4}$, L., \& Faulkner ${ }^{5}$, J.

1 Faculty of Health Sciences, University of Southampton, Southampton, UK.

2 Respiratory Unit, Starship Hospital, Auckland, New Zealand.

3 Faculty of Philosophy II, Julius Maximilians University, Würzburg, Germany.

4 School of Sport \& Exercise, Massey University, Wellington, 6021, New Zealand.

5 Department of Sport \& Exercise, University of Winchester, Winchester, UK

\section{Corresponding Author:}

Dr Danielle Lambrick

Faculty of Health Sciences

University of Southampton

Highfield Campus

Southampton

SO17 1BJ, UK.

Phone: +44 (0)23 80595916

Fax: +44 (0)23 80597900

Email: D.M.Lambrick@soton.ac.uk

NB. This is an Accepted Manuscript of an article published by Taylor \& Francis in the Journal of Sports Sciences on 03/05/2015, available online:

http://www.tandfonline.com/10.1080/02640414.2015.1048521 


\begin{abstract}
This study assessed the effectiveness of a six-week, high-intensity, games-based intervention on physiological and anthropometric indices of health, in normal weight $(\mathrm{n}=26 ; 32.5 \pm 8.9 \mathrm{~kg})$ and obese ( $\mathrm{n}=29 ; 49.3 \pm 8.9 \mathrm{~kg}$ ) children ( $\mathrm{n}=32$ boys, 23 girls), aged 8-10 years. Children were randomised into an exercise or control group. The exercise group participated in a twice-weekly, 40 minute active games intervention, alongside their usual school physical education classes. The control group did not take part in the intervention. Before and after the intervention, participants completed both a maximaland submaximal graded exercise test. The submaximal exercise test comprised of a six minute, moderate- and six minute heavy intensity bout, interspersed with a five minute recovery. The exercise group demonstrated improvements in maximal oxygen uptake $\left(51.4 \pm 8.5 \mathrm{vs} 54.3 \pm 9.6 \mathrm{ml} \cdot \mathrm{kg}^{-1} \cdot \mathrm{min}^{-1}\right.$ ) and peak running speed $\left(11.3 \pm 1.6\right.$ vs $\left.11.9 \pm 1.6 \mathrm{~km} \cdot \mathrm{h}^{-1}\right)$, and a reduction in the oxygen cost of submaximal exercise between assessments $(P<.05)$. A decrease in waist circumference and increase in muscle mass were observed between assessments for the obese participants randomised to the intervention (both $P<.05$ ). This study demonstrates that a short-term, high-intensity games intervention, may elicit positive changes in physiological and anthropometric indices of health, in normal weight and obese children.
\end{abstract}

Keywords: HIIT, paediatric, exercise, $\mathrm{VO}_{2}$ peak, obesity. 


\section{Introduction}

Physical activity during early childhood has been shown to have positive effects on adult health habits (Trudeau, Laurencelle, Tremblay, Rajic \& Shephard, 1999), and reduce incidences of cardiovascular disease (CVD), metabolic diseases (obesity, type II diabetes, etc.) and premature death (Warburton, Nicol, \& Bredin, 2006). However, population-based studies have shown that only $42 \%$ of 6 to 11-year-old children obtain the recommended 60 minutes per day of moderate-to-vigorous physical activity (Troiano, et al., 2008).

Unlike adults, children's habitual physical activity patterns are highly intermittent in nature, characterised by rapid changes from rest to vigorous physical activity (Howe, Freedson, Feldman, \& Osganian, 2010). This intensity differential is of particular importance when considering that time spent in vigorous-intensity activity is more strongly associated with a number of positive health outcomes (improved cardiorespiratory fitness, waist circumference, systolic blood pressure, \& BMI) than light- or moderate-intensity activity (Carson et al., 2014; Hay et al., 2012). In this regard, shortterm, high-intensity, intermittent [aerobic] training (HIIT) programmes may be efficacious for the health and fitness of children, yet, more experimental work is needed to establish the optimal volume and safety of high (vigorous) intensity exercise in conferring various health benefits in youth (Carson et al., 2014).

In addition to the known cardiometabolic health benefits, short-term, HIIT can improve aerobic performance (maximal oxygen uptake $\left[\mathrm{VO}_{2} \mathrm{max}\right]$, maximal aerobic velocity, endurance performance) (Baquet et al., 2002, 2010; Baquet, Guinhouya, Dupont, Nourry \& Berthoin, 2004; Lau et al., 2014), and anaerobic capacity in children (Ratel, et al., 2004). Although these findings are encouraging, previous studies have tended to prescribe exercise with a focus on cycling and running (Baquet et al., 2010; Barker, Day, Smith, Bond, \& Williams, 2014; Lau et al., 2014; McManus, Cheng, Leung, Yung, \& Macfarlane, 2005). However, Biddle, Gorley and Stensel (2004) have questioned the utility of structured activity programmes for children, suggesting that the provision of such programmes inadequately prepares children for the typically unstructured nature of adult activity. Of further relevance is the observation that children's habitual physical activity patterns are characteristically governed by participation in child-specific games or 'unpredictable' sporting 
activities (i.e., football, netball) (Nassis et al., 2005). Given that intrinsic motivation, or a child's level of enjoyment, is also a strong predictor of physical activity participation in young children (Sebire, Jago, Fox, Edwards, \& Thompson, 2013), interventions should be designed to optimise children's enjoyment of physical activity.

The purpose of this study was to assess the effectiveness of a six-week, HIIT, child-specific games intervention on improving physiological and anthropometrical indices of health and fitness in children of differing body mass (normal weight vs. obese), aged 8-10 years. We hypothesised that regular exercise participation would lead to improved measures of body composition (body mass, waist circumference) and significant improvements in physiological parameters, specifically, peak oxygen consumption and a reduction in the oxygen cost of submaximal exercise, for both normal weight and obese children.

\section{Methods}

Participants

Fifty five children ( $\mathrm{n}=32$ boys, 23 girls), aged 8-10 years, volunteered to take part the study. Body mass index (BMI) percentiles were used to categorise children as either normal weight (NW; $5^{\text {th }}-85^{\text {th }}$ percentile) or obese $\left(\mathrm{OB} ; \geq 95^{\text {th }}\right.$ percentile) (WHO Child Growth Standards: http://www.who.int/growthref/en/; de Onis et al., 2007). The predicted mean age at peak height velocity was calculated for NW (12.3 \pm 0.9 y) and OB children (11.6 \pm 0.8 y) to provide an indication of their biological maturity (Mirwald, Baxter-Jones, Bailey, \& Beunen, 2002). All parents / guardians completed a standardised health screening questionnaire, which ascertained that all children were asymptomatic of illness, disease and pre-existing injuries. Parent / guardian consent and child assent were obtained prior to participation. Ethical approval was granted for this study by the relevant institutional ethics committee. 


\section{Sample Size}

On the basis of the findings of McCann and Adams (2002), and when using a two-sided 5\% significance level and a power of $80 \%$, a minimum sample size of 11 participants per group was calculated to detect a statistical difference in our primary outcome measure (oxygen cost of exercise).

\section{Procedures}

All participants took part in two laboratory-based graded exercise tests (GXT) to maximal aerobic capacity ( $\sqrt{\mathrm{L}} \mathrm{O}_{2}$ peak), and two submaximal steady-state exercise protocols on a motorized treadmill (True 825, Fitness Technologies, St Louis, USA) within a thermoneutral environment (21.1 $\pm 1.8^{\circ} \mathrm{C} ; 36.8 \pm 4.6 \% ; 755 \pm 6 \mathrm{mmHg}$ ). All participants completed a GXT and a submaximal exercise test at baseline and follow-up. Each submaximal test was completed 48-72 hours after the GXT. Prior to the commencement of each GXT, participants' anthropometric measures (stature, seated height, body mass, waist circumference; fat mass and muscle mass [InBody Biospace 230, USA]) were recorded. All children were then familiarised to a range of treadmill speeds $\left(4 \mathrm{~km} \cdot \mathrm{h}^{-1}, 6 \mathrm{~km} \cdot \mathrm{h}^{-1} \& 8\right.$ $\mathrm{km} \cdot \mathrm{h}^{-1}$ ) and the testing equipment (facemask, heart rate monitor, etc.) prior to initiating the GXT.

Throughout all exercise tests, the treadmill grade was set at $1 \%$, respiratory variables (oxygen uptake $\left[{ }_{\mathrm{L}} \mathrm{O}_{2}\right]$; carbon dioxide $\left[\sqrt{\mathrm{L}} \mathrm{CO}_{2}\right]$; minute ventilation $\left[\overline{\mathrm{K}}_{\mathrm{E}}\right]$; respiratory exchange ratio [RER]) were recorded using a breath-by-breath automatic gas exchange system (Sensormedics Corporation, Yorba Linda, CA, USA), and heart rate was monitored (Polar Electro T31, Kempele, Finland). All physical and physiological outputs were concealed from the participants.

\section{GXT to $\sqrt{\mathrm{L}} \mathrm{O}_{2}$ peak}

A discontinuous incremental test was used to ascertain participants' GET, $\sqrt{2} \mathrm{O}_{2}$ peak and maximal heart rate (HRmax) from the GXT (Lambrick, Faulkner, Westrupp, \& McNarry, 2013). Children commenced the test at $4 \mathrm{~km} \cdot \mathrm{h}^{-1}$ and walked at that intensity for 1 -minute. The treadmill speed was then slowed to a stop $\left(0 \mathrm{~km} \cdot \mathrm{h}^{-1}\right)$ to allow a 1-minute recovery, before being increased again to a speed of $6 \mathrm{~km} \cdot \mathrm{h}^{-1}$ for a further minute of exercise. A 1-minute recovery was implemented 
following each minute of active exercise. Increments of $1 \mathrm{~km} \cdot \mathrm{h}^{-1}$ continued with this protocol until a speed of $8 \mathrm{~km} \cdot \mathrm{h}^{-1}$ was accomplished. Thereafter, increments in running speeds of $0.5 \mathrm{~km} \cdot \mathrm{h}^{-1}$ occurred (8.5, $9.0 \mathrm{~km} \cdot \mathrm{h}^{-1}$ etc.) until volitional exhaustion. Test termination was based upon volitional exhaustion and the achievement of $\sqrt{2} \mathrm{O}_{2}$ peak. Participants' subjective perception of exertion (RPE) was determined upon completion of each stage using the Eston-Parfitt (E-P) curvilinear scale (Lambrick, Rowlands, \& Eston, 2011).

\section{Submaximal exercise test}

The V-slope method (Beaver, Wasserman, \& Whipp, 1986) was used to analyse the slopes of $\sqrt{\mathrm{L}} \mathrm{O}_{2}$ and $\sqrt{\mathrm{L}} \mathrm{CO}_{2}$ volume curves from each GXT to determine the running speed equivalent with $90 \%$ GET. The running speed equivalent to $40 \%$ delta ( $\Delta$; difference between GET and $\mathrm{VO}_{2}$ peak) was subsequently calculated. The $90 \%$ GET (moderate) and $40 \% \Delta$ (heavy) exercise intensities (i.e., running speeds) were verified by three independent researchers and were used for each subsequent submaximal exercise test.

Following a 5-minute warm-up at $4 \mathrm{~km} \cdot \mathrm{h}^{-1}$ (walk), and a suitable rest period to return heart rate to baseline, all participants ran at treadmill speeds equivalent to $90 \%$ GET and $40 \% \Delta$. Participants ran for six-minutes at each intensity, and a five-minute recovery period was implemented between each exercise bout.

\section{Randomisation}

Children were randomly assigned to either an exercise (EX) or control (CON) group using stratified randomisation procedures where body mass was treated as a covariate. This ensured even representation of NW and OB children in both the EX and CON groups.

HIIT, child-specific, exercise intervention

Participants randomised to EX completed a supervised six-week, HIIT, child-specific games programme. This included participation in twice-weekly 60-minute exercise sessions, of which children were physically active for 40 -minutes each session. There was a minimum 48-hour recovery 
period between sessions. These sessions were conducted outside of the children's normal Physical Education lessons $\left(1 \mathrm{hr} \cdot \mathrm{wk}^{-1}\right)$ and lunch period, but within school hours, and were therefore considered supplementary exercise.

A two-week pilot trial, using children ( $\mathrm{n}=16$; mixed ethnicity, aged: 8-11 y) from a school that was separate to this study, demonstrated that children could repeatedly sustain 6-minutes of highintensity exercise followed by 2-minutes of recovery. In the current study, to increase motivation, enjoyment and adherence, and to ensure children took part in each game at a high-intensity, different games $(n=14)$ were used for each 6-minute exercise period (Supplementary Table). The 2-minute recovery period allowed practitioners to provide instructions concerning the proceeding game activity. Children took part in six games per session, plus a 4-minute circuit. Heart rate was monitored continuously throughout each exercise session (Polar Team ${ }_{2}$ system, POLAR, Oulu, Finland). On completion of the six-week intervention, children were asked to complete the Physical Activity Enjoyment Scale (PACES); a valid and reliable marker of perceived enjoyment (Kendzierski \& DeCarlo, 1991). This 16-item scale allows children to rate a series of enjoyment markers using a 5point likert, ranging from 'disagree a lot' to 'agree a lot'. PACES is presented as a total score (out of 80) \pm SD.

The EX and CON groups continued to attend their weekly Physical Education classes, but no additional exercise sessions were included for CON.

\section{Statistical analysis}

The $\sqrt{2} \mathrm{O}_{2}$ peak in this study has been presented in relation to measured body mass $\left(\mathrm{mL} \cdot \mathrm{kg}^{-}\right.$ $\left.{ }^{1} \cdot \mathrm{min}^{-1}\right)$, fat free mass $\left(\mathrm{mL} \cdot \mathrm{kg}^{\mathrm{FFM}} \cdot \mathrm{min}^{-1}\right)$ and as a proportion to $\sqrt{\mathrm{L}} \mathrm{O}_{2}$ peak $\left(\% \sqrt{\mathrm{L}} \mathrm{O}_{2}\right.$ peak from submaximal tests). As identical findings were observed when using allometric scaling or when data was scaled to body mass $\left(\mathrm{mL} \cdot \mathrm{kg}^{-1} \cdot \mathrm{min}^{-1}\right)$, findings are reported in relation to the latter.

A series of independent sample t-tests were used to compare anthropometric variables between groups (EX, CON) at baseline, and within bodyweights for OB (EX vs. CON) and NW (EX vs. CON). A series of 3-factor repeated measures ANOVA; Test (baseline, post-intervention) $\mathrm{x}$ 
Condition (EX, CON) x BMI (OB, NW) were used to compare changes in anthropometric variables. A similar analysis was used to compare physiological ( $\sqrt{\mathrm{K}}_{2}$ peak, HRmax, $\sqrt{\mathrm{E}}_{\mathrm{E}}$ peak), perceptual (RPE) and physical (running speed) markers identified from the GXTs to $\mathbb{L}_{2}$ peak. These variables were also compared from the moderate (90\% GET) and heavy $(40 \% \Delta)$ intensity submaximal exercise tests using the same statistical procedure. In the preceding analyses, if Mauchly's test of sphericity was violated, a Greenhouse-Geisser correction factor was employed. Where a significant interaction was located, a Tukey's honestly significant difference (HSD) test was implemented. The Tukey’s HSD calculates the minimum raw score mean difference that must be attained to declare significance between any two groups. Alpha was set at $\alpha=.05$. All data was analysed using the statistical package SPSS for windows, PC software, version 20.0.

\section{Results}

HIIT, child specific, exercise intervention

Children randomised to EX attended $96 \%$ of all available sessions. During the six-week intervention, children's average heart rate was $175 \pm 8 \mathrm{~b} \cdot \min ^{-1}$ ( 86\% HRmax) during each of the games which were implemented. A HRpeak of $191 \pm 8 \mathrm{~b} \cdot \min ^{-1}$ (93\% HRmax) was also observed. There were no adverse events, and children reported a PACES score (out of 80) of $71.7 \pm 3.9$ (average score per item: $4.48 \pm 0.24$ [out of 5]).

\section{Anthropometric data}

There were no differences in any of the anthropometric characteristics between EX and CON at baseline (all $P>.05$; Table 1$)$. Despite no differences in age $(P>.05)$, significantly greater anthropometric values were observed for OB than NW children at baseline (all $P<.05$ ). Body mass $\left(40.4 \pm 8.6\right.$ vs. $\left.41.4 \pm 9.3 \mathrm{~kg} ; \mathrm{F}_{(1,51)}=23.59, P<.001\right)$ and stature $(140.5 \pm 9.0$ vs. $142.1 \pm 9.0 \mathrm{~cm}$; $\left.\mathrm{F}_{(1,51)}=56.44, P<.001\right)$ significantly increased between baseline and post-intervention assessments, respectively. There were no differences in the rate of change in body mass or stature for EX and $\mathrm{CON}$, or for NW and $\mathrm{OB}$, between baseline and post-intervention assessments $(P>.05)$. A significant 
Test by Condition by BMI interaction was revealed for waist circumference $\left(\mathrm{F}_{(1,51)}=4.61, P<.05\right)$ and muscle mass $\left(\mathrm{F}_{(1,51)}=6.42, P<.05\right)$. Tukey's HSD only demonstrated a significant decrease in waist circumference- (73.2 \pm 7.9 vs. $70.9 \pm 8.2 \mathrm{~kg})$ and a significant increase in muscle mass $(17.1 \pm 3.4$ vs. $18.1 \pm 2.2 \mathrm{~kg}$ ) between baseline and post-intervention, respectively, for the OB participants randomised to EX. There were no other differences observed in the rate of change in waist circumference or muscle mass for the NW participants randomised to EX, or for the OB and NW participants randomised to CON $(P>.05)$.

\section{GXT to $\sqrt{\mathrm{L}} \mathrm{O}_{2}$ peak}

A significant Test by Condition interaction was observed for $\sqrt{\mathrm{L}} \mathrm{O}_{2}$ peak $\left(\mathrm{F}_{(1,51)}=5.60, P<.05\right)$ and peak running speed $\left(\mathrm{F}_{(1,51)}=7.01, P<.05\right.$; Table 2). Post-hoc analysis demonstrated a significant increase in ${ }^{\mathrm{K}} \mathrm{O}_{2}$ peak and peak running speed between baseline and post-intervention for EX but not for CON. The changes in $\sqrt{2} \mathrm{O}_{2}$ peak for $\mathrm{EX}$ between baseline and post-intervention were not moderated by BMI $(P>.05)$. However, further analysis revealed that the aforementioned peak running speed interaction was moderated by BMI $\left(\mathrm{F}_{(1,51)}=6.06, P<.05\right)$, with the observed improvements only evident for NW children. A higher relative $\dot{\mathrm{V}} \mathrm{O}_{2}$ peak was observed for NW children at both baseline (58.1 \pm 6.9 vs. $48.6 \pm 7.4 \mathrm{~mL} \cdot \mathrm{kg}^{-1} \cdot \mathrm{min}^{-1}$, respectively; $\left.P<.001\right)$ and postintervention (58.4 \pm 7.3 vs. $50.6 \pm 8.1 \mathrm{~mL} \cdot \mathrm{kg}^{-1} \cdot \mathrm{min}^{-1}$, respectively; $P<.001$ ), regardless of Condition (EX, CON). There were no differences between Conditions or BMI groups for HR and perceived exertion (all $P>.05$ ).

Significant interactions were also revealed for $\dot{\mathrm{V}} \mathrm{O}_{2}\left(\mathrm{~mL} \cdot \mathrm{kg}^{-1} \cdot \mathrm{min}^{-1}\right)$ and $\% \dot{\mathrm{V}} \mathrm{O}_{2}$ peak at GET $(P<.05)$, as demonstrated in Table 2. Significant decreases in $\dot{\mathrm{V}} \mathrm{O}_{2}$ and $\% \dot{\mathrm{V}} \mathrm{O}_{2}$ peak were observed between baseline and post-intervention for EX. 
A Test by Condition interaction was observed for $\overline{\mathrm{K}}_{2}\left(\mathrm{~mL} \cdot \mathrm{kg}^{-1} \cdot \mathrm{min}^{-1}\right)$, \% $\overline{\mathrm{L}}_{2}$ peak and $\dot{\mathrm{V}}_{\mathrm{E}}$, with significantly lower values reported at post-intervention than baseline for EX, but not for CON (all $P<.05$; Table 3). A similar interaction was observed when comparing the running speed at $90 \%$ GET $(P<.05)$, although post-hoc analysis demonstrated a significant increase in running speed between the baseline and post-intervention assessment for EX. When expressed as a proportion of maximal running speed, a Test by Condition interaction was not observed ( $P>.05$; Table 3$)$. BMI did not moderate any of the physiological markers ( $\left(\sqrt{\mathrm{L}} \mathrm{O}_{2}\right.$, HR, etc.; $P>.05$ ).

\section{Submaximal exercise test; Heavy intensity $(40 \% \Delta)$}

Similar to the moderate intensity domain, a significant Test by Condition interaction was revealed for $\sqrt{\mathrm{L}} \mathrm{O}_{2}\left(\mathrm{~mL} \cdot \mathrm{kg}^{-1} \cdot \mathrm{min}^{-1}\right)$, \% $\overline{\mathrm{K}}_{2}$ peak and $\overline{\mathrm{K}}_{\mathrm{E}}(P<.05)$, with lower values reported at the post-intervention assessment than baseline for EX (Table 4). A Test by BMI interaction was observed for $\% \dot{\mathrm{V}} \mathrm{O}_{2}$ peak $(P<.05)$, with a significantly greater reduction between the baseline and postintervention assessments for OB ( $80 \pm 8$ vs. $75 \pm 9 \%$, respectively) compared to NW (76 \pm 7 vs. $75 \pm$ 8\%, respectively). ANOVA also revealed a Test by Condition interaction for the running speed at $40 \% \Delta(P<.05)$. A significant increase in running speed (between baseline and post-intervention assessments) was only observed for EX, although no differences were observed when expressed as a proportion of maximal running speed $(P>.05$; Table 4$)$.

\section{Discussion}

The purpose of this study was to assess the effectiveness of a short-term, HIIT, child-specific games intervention on physiological and anthropometric variables of normal weight (NW) and obese (OB) children. The main findings from this study demonstrate that six-weeks of regular, child-specific HIIT, over and above usual physical activity participation, can elicit: i) improvements in peak oxygen uptake and peak running speed; ii) a reduction in the $\mathrm{O}_{2}$ cost of submaximal exercise, and iii) improvements in body composition (waist circumference, muscle mass) in OB children. Thus, 
participation in child-specific HIIT can be beneficial for a number of health-related outcomes in prepubertal children.

Previous research has shown that HIIT is a highly effective training method for both adults (Gibala, Little, MacDonald, \& Hawley, 2012; Hottenrott, Ludyga, \& Schulze, 2012) and children (Baquet et al., 2010; Barker et al., 2014; Corte de Araujo et al., 2012; Lau et al., 2014). Lau et al. (2014) have recently demonstrated that a six-week HIIT intervention was effective in improving functional walking ability and endurance performance in a cohort of overweight children, aged 9-11 years. However, in their study, endurance performance was determined by distance covered during the field-based Yo-Yo test, which was used as an indicator of improved physical fitness. Maximal exercise testing, as utilised in the current study, is considered the gold standard measurement of aerobic fitness. In this regard, the children in the current study showed a statistical, 7\% improvement in $\sqrt{\mathrm{K}} \mathrm{O}_{2}$ peak, which is of a similar magnitude to that observed by Baquet et al. (2002) $(+8.2 \%)$ and Rowland and Boyajian (1995) (+ 6.3\%), for prepubertal children during HIIT (running) and aerobic endurance training. Our finding has particular practical significance though when considering the games-based intervention that was employed in this study and its potential for future exercise adherence.

Structured intermittent exercise has been found to be more reinforcing of positive physical activity behaviour compared to continuous intensity activity (Barkley, Epstein \& Roemmich, 2009). But, as dynamic 'games' inherently mimic a child's unstructured, habitual physical activity patterns (Biddle et al., 2004; Howe, Freedson, Alhassan, Feldman, \& Osganian, 2012), and as 'play' is strongly linked to increased enjoyment and intrinsic motivation, possibly through enhanced social interaction (Nielsen et al., 2014), it is plausible that the level of enjoyment during a games-based intervention, as was employed in this study, may improve exercise adherence over and above that observed for more regimented physical activity programmes. This remains to be conclusively determined, however, as a direct comparison of differing HIIT programmes was not conducted in the current study. Nor was a long-term follow-up conducted to see if weekly physical activity participation increased in our paediatric cohort once the exercise intervention was complete. 
However, the children in our study were shown to enjoy participating in the HIIT games-based intervention, as demonstrated by a 96\% attendance rate and high PACES score ( 72 out of 80 ). The games-based intervention employed in this study has high ecological validity, and theoretically could enhance future exercise adherence in normal weight and obese children.

Although no statistical differences were observed in heart rate at moderate and heavy intensities between baseline and post-intervention assessments, a reduction in the $\mathrm{O}_{2}$ cost to perform submaximal exercise was shown for both the $\mathrm{OB}$ and NW children randomised to the exercise condition. During both the moderate and heavy submaximal intensity domains, lower $\sqrt{\mathrm{K}} \mathrm{O}_{2}(-7 \%)$ and $\sqrt{Z}_{E}(-6 \%)$ measurements, but higher absolute running speeds $(+5 \%)$, were recorded during the postintervention assessment. This is in contrast to previous research which has shown similar or greater submaximal $\sqrt{\mathrm{K}} \mathrm{O}_{2}$ values following either HIIT or a traditional endurance-focused training programme (Baquet et al., 2002; McManus et al., 2005). It may be postulated that this finding, coupled with the elevated $\sqrt{\mathrm{K}} \mathrm{O}_{2}$ peak, demonstrates an enhanced exercise tolerance in the children who participated in the exercise intervention, similar to previous research (Barker et al., 2014; Sperlich et al., 2011). Interestingly, the obese children demonstrated a greater improvement in their ability to perform submaximal exercise (\% $\sqrt{\mathrm{L}} \mathrm{O}_{2}$ peak) in the heavy intensity domain, post-intervention, than the normal weight children ( $4 \%$ vs. $1 \%$, respectively). This is likely somewhat related to variations in baseline fitness between the two groups. As normal weight children were statistically fitter (greater ${ }^{2} \mathrm{O}_{2}$ peak) at baseline compared to obese children, we can assume that the greater potential for change in the obese group was realised as a result of the exercise intervention. Given that children have an inherently superior aerobic capacity at moderate exercise intensities (below GET), it is unsurprising that this difference was only observed for the high intensity exercise domain as this reflects a positive training effect of the HIIT intervention (i.e., specificity). However, it is also important to consider a potential confounding aspect of our methodology, in that the short recovery period which was implemented between the moderate and heavy exercise intensity bouts may have acted as a primer for the heavy intensity bout. Given that obese children demonstrate a greater time constant and phase II gain in their oxygen uptake kinetics response to high intensity exercise compared to their normal 
weight counterparts (Lambrick et al., 2013), it is plausible that any priming effects may have more significantly influenced the obese children in this study.

Obese children randomised to the exercise group experienced a significant reduction in waist circumference (-3\%) and a significant increase in muscle mass (+ 6\%). This finding supports Corte de Araujo et al. (2012) who showed significant changes in overall body mass and BMI of obese 8-12 year-old children following 12-weeks of HIIT. Reductions in sum of skinfolds have also been noted by Lau et al. (2014) following six-weeks of HIIT in overweight children. We can assume, since similar positive changes were not observed in the control group in our study, that the games-based exercise intervention played a pivotal role in these beneficial changes in body composition. It should be noted however that the calculations of peak height velocity merely estimate biological maturity. As we were unable to undertake Tanner staging with our participant sample, we were unable to ascertain whether all children were in fact prepubertal. Moreover, as we did not control for diet during the intervention, we are unable to determine the influence of dietary habits on body composition changes between the EX and CON groups.

It should be noted that this is the first study to utilise a child-specific, games-based, high intensity exercise intervention for the purpose of improving indices of health in normal weight and obese paediatric groups. Continuous physiological monitoring throughout the exercise intervention sessions confirmed that children were working at a sufficient intensity (average: 93\% HRmax) to elicit positive changes in their functional capacity $\left(\mathrm{VO}_{2}\right.$ peak, peak speed, $\% \mathrm{VO}_{2}$ peak $)$ and aspects of body composition, unlike previous exercise interventions (Lau et al., 2014). The games-based intervention demonstrates high ecological validity in that children were performing activities that augment social interaction and enjoyment, and mimic their usual patterns of play. The intervention was also undertaken at the children's schools, and the school environment is considered highly important when implementing physical activity strategies for children (Carrel et al., 2005; Howe et al., 2012). However, the rapport between each child and the exercise instructor may bare some relevance to the level of engagement and enjoyment with the exercise intervention. Furthermore, it was not logistically possible to quantify children's physical activity outside of the exercise 
intervention (for both EX and CON) and thus, we do not know whether children may have increased or decreased their normal physical activity behaviour throughout the study period.

\section{Conclusion}

The present study has demonstrated that just six-weeks of high-intensity training, using games-based exercises can improve a number of health-related outcome measures (cardiorespiratory performance and anthropometric markers) in children, aged 8-10 years. In particular, this study

demonstrated improvements in maximal functional capacity ( $\sqrt{\mathrm{L}} \mathrm{O}_{2}$ peak and peak running speed), a reduced $\mathrm{O}_{2}$ cost during submaximal exercise, and improved indices of body composition (waist circumference, muscle mass) for those children randomised to the exercise programme. Furthermore, these changes were observed, to varying degrees, in both the obese and normal weight children. A games-based, high-intensity exercise intervention may augment feelings of enjoyment and intrinsically motivate children to continue to engage in exercise following completion of a programme, but this needs to be established in future research. Future research should also identify the optimal duration of high intensity exercise for improving physical, physiological and cognitive health in young children. 


\section{References}

Baquet, G., Berthoin, S., Dupont, G., Blondel, N., Fabre, C., \& van Praagh, E. (2002). Effects of high intensity intermittent training on peak VO2 in prepubertal children. International Journal of Sports Medicine, 23, 439-444. doi:10.1055/s-2002-33742.

Baquet, G., Gamelin, F. X., Mucci, P., Thevenet, D., Van Praagh, E., \& Berthoin, S. (2010). Continuous vs. interval aerobic training in 8- to 11-year-old children. Journal of Strength and Conditioning Research, 24, 1381-1388. doi:10.1519/jsc.0b013e3181d1575a.

Baquet, G., Guinhouya, C., Dupont, G., Nourry, C., \& Berthoin, S. (2004). Effects of a short-term interval training program on physical fitness in prepubertal children. Journal of Strength and Conditioning Research, 18, 708-713. doi:10.1519/13813.1.

Barker, A. R., Day J., Smith A., Bond B., \& Williams, C.A. (2014). The influence of 2 weeks of low volume high-intensity interval training on health outcomes in adolescent boys. Journal of Sports Science and Medicine, 32, 757-765. doi:10.1080/02640414.2013.853132.

Barkley, J. E., Epstein, L. H., \& Roemmich, J. N. (2009). Reinforcing value of interval and continuous physical activity in children. Physiology and Behavior, 98, 31-36. doi:10.1016/j.physbeh.2009.04.006.

Beaver, W., Wasserman, K., \& Whipp, B. (1986). A new method for detecting anaerobic threshold by gas exchange. Journal of Applied Physiology, 60, 2020-2027. Retrieved from http://jap.physiology.org/.

Biddle, S. J. H., Gorely, T., \& Stensel, D. J. (2004). Health-enhancing physical activity and sedentary behaviour in children and adolescents. Journal of Sports Sciences, 22, 679-701. doi:10.1080/02640410410001712412. 
Carrel, A. L., Clark, R. R., Peterson, S. E., Nemeth, B. A., Sullivan, J., \& Allen, D. B. (2005). Improvement of fitness, body composition, and insulin sensitivity in overweight children in a schoolbased exercise program: a randomized, controlled study. Archives of Pediatrics and Adolescent Medicine, 159, 963-968. doi:10.1001/archpedi.159.10.963.

Carson, V., Rinaldi, RL., Torrance, B., Maximova, K., Ball, G. D. C., Majumdar, S. R., ... McGavock, J. (2014). Vigorous physical activity and longitudinal associations with cardiometabolic risk factors in youth. International Journal of Obesity, 38, 16-21. doi: 10.1038/ijo.2013.135.

Corte de Araujo, A. C., Roschel, H., Picanço, A. R., do Prado, D. M. L., Villares, S. M. F., Lúcia de Sá Pinto, A., \& Gualano, B. (2012). Similar health benefits of endurance and high-intensity interval training in obese children. PLoS ONE, 7, e42747. doi:10.1371/journal.pone.0042747.

de Onis, M., Onyango, A. W., Borghi, E., Siyam, A., Nishida, C., \& Siekmann, J. (2007). Development of a WHO growth reference for school-aged children and adolescents. Bulletin of the World Health Organisation, 85, 660-7.

Gibala, M. J., Little, J. P., MacDonald, M. J., \& Hawley, J. A. (2012). Physiological adaptations to low-volume, high-intensity interval training in health and disease. Journal of Physiology, 590, 10771084. doi:10.1113/jphysiol.2011.224725.

Hay, J., Maximova, K., Durksen, A., Caron, V., Rinaldi, R. L., Torrance, B., .. McGavock, J. (2012). Physical activity intensity and cardiometabolic risk in youth. Archives of Pediatric Adolescent Medicine, 166, 1022-1029. doi: 10.1001/archpediatrics.2012.1028. 
Hottenrott, K., Ludyga, S., \& Schulze, S. (2012). Effects of high intensity training and continuous endurance training on aerobic capacity and body composition in recreationally active runners. Journal of Sports Science and Medicine, 11, 483-488. Retrieved from http://www.jssm.org/.

Howe, C. A., Freedson, P. S., Alhassan, S., Feldman, H. A., \& Osganian, S. K. (2012). A recess intervention to promote moderate-to-vigorous physical activity. Pediatric Obesity, 7, 82-88. doi:10.1111/j.2047-6310.2011.00007.x.

Howe, C. A., Freedson, P. S., Feldman, H. A., \& Osganian, S. K. (2010). Energy Expenditure and Enjoyment of Common Children's Games in a Simulated Free-Play Environment. Journal of Pediatrics, 157, 936-942.e2. doi:10.1016/j.jpeds.2010.06.041.

Kendzierski, D., \& DeCarlo, K. J. (1991). Physical activity enjoyment scale: Two validation studies. Journal of Sport \& Exercise Psychology, 13, 50-64. Retrieved from http://journals.humankinetics.com/jsep.

Lambrick, D., Faulkner, J., Westrupp, N., \& McNarry, M. (2013). The influence of body weight on the pulmonary oxygen uptake kinetics in pre-pubertal children during moderate- and heavy intensity treadmill exercise. European Journal of Applied Phyiology, 113, 1947-1955. doi:10.1007/s00421013-2625-8.

Lambrick, D.M., Rowlands, A.V., \& Eston, R.G. (2011). The perceptual response to treadmill exercise using the Eston-Parfitt Scale and marble dropping task, in children age 7 to 8 years. Pediatric Exercise Science, 23, 36-48. doi:10.1111/j.1469-8986.2009.00826.x.

Lau, P. W., Wong, D. P., Ngo, J. K., Liang, Y., Kim, C. G., \& Kim, H. S. (2014). Effects of highintensity intermittent running exercise in overweight children. European Journal of Sport Science, 11, 1-9. doi:10.1080/17461391.2014.933880. 
McCann, D. J., \& Adams, W. C. (2002). A theory for normalising resting $\mathrm{VO}_{2}$ for differences in body size. Medicine and Science in Sports and Exercise, 34, 1382-1390. Retrieved from: http://www.journals.lww.com/acsm-msse/pages/issuelist.aspx

McManus, A. M., Cheng, C. H., Leung, M. P., Yung, T. C., \& Macfarlane, D. J. (2005). Improving aerobic power in primary school boys: a comparison of continuous and interval training. International Journal of Sports Medicine, 26, 781-786. doi:10.1055/s-2005-837438.

Mirwald, R. L., Baxter-Jones, A. D. G., Bailey, D. A., \& Beunen, G. P. (2002). An assessment of maturity from anthropometric measurements. Medicine and Science in Sports and Exercise, 34, 689694. doi:/10.1097/00005768-200204000-00020.

Nassis, G. P., Papantakou, K., Skenderi, K., Triandafillopoulou, M., Kavouras, S. A., Yannakoulia, M., ... Sidossis, L. S. (2005). Aerobic exercise training improves insulin sensitivity without changes in body weight, body fat, adiponectin, and inflammatory markers in overweight and obese girls. Metabolism, 54, 1472-1479. doi:10.1016/j.metabol.2005.05.013.

Nielsen, G., Wikman, J. M., Jensen, C. J., Schmidt, J. F., Gliemann, L., \& Andersen, T. R. (2014). Health promotion: The impact of beliefs of health benefits, social relations and enjoyment on exercise continuation. Scandinavian Journal of Medicine \& Science in Sports, 24, 66-75. doi:10.1111/sms.12275.

Ratel, S., Lazaar, N., Dore, E., Baquet, G., Williams, C. A., Berthoin, S., . . Duche, P. (2004). Highintensity intermittent activities at school: controversies and facts. J Sports Med Phys Fitness, 44, 272280. 
Rowland, T. W., \& Boyajian, A. (1995). Aerobic response to endurance exercise training in children. Pediatrics Clinics of North America, 96, 654-658.

Sebire, S. J., Jago, R., Fox, K. R., Edwards, M. J., \& Thompson, J. L. (2013). Testing a selfdetermination theory model of children's physical activity motivation: a cross-sectional study. International Journal of Behavioural Nutrition and Physical Activity, 10, 111. doi:10.1186/14795868-10-111.

Sperlich, B., De Marees, M., Koehler, K., Linville, J., Holmberg, H. C., \& Mester, J. (2011). Effects of 5 weeks of high-intensity interval training vs. volume training in 14-year-old soccer players. Journal of Strength and Conditioning Research, 25, 1271-1278. doi:10.1519/jsc.0b013e3181d67c38.

Troiano, R. P., Berrigan, D., Dodd, K. W., M^asse, l. C., Tilert, T., \& Mcdowell, M. (2008). Physical activity in the United States measured by accelerometer. Medicine and Science in Sports and Exercise, 40, 181-188. doi:10.1249/mss.0b013e31815a51b3.

Trudeau, F., Laurencelle, L., Tremblay, J., Rajic, M., \& Shephard, R. J. (1999). Daily primary school physical education: effects on physical activity during adult life. Medicine and Science in Sports and Exercise, 31,111-117. Retrieved from: http://www.journals.lww.com/acsm-msse/pages/issuelist.aspx

Warburton, D. E., Nicol, C. W., \& Bredin, S. S. (2006). Health benefits of physical activity: the evidence. Canadian Medical Association Journal, 174, 801-809. doi:10.1503/cmaj.051351.

WHO. (2014). The WHO child growth standards. Retrieved from http://www.who.int/growthref/who2007_bmi_for_age/en/ 